\title{
Evaluation and analysis for Haze discrimination criteria in Jiangsu Province
}

\author{
Song Gao', a, $\mathrm{Li} \mathrm{Li}^{2, \mathrm{~b}}$, Yu Wang ${ }^{3, \mathrm{c}}$, Yanqing Zhang ${ }^{4, \mathrm{~d}}$
}

${ }^{1}$ Electric power research institute of Jiangsu electric power company, Nanjing 211103,China;

${ }^{2}$ Nanjing University of Information Science and Technology, Nanjing 210044,China;

${ }^{3}$ Nanjing University of Information Science and Technology, Nanjing 210044,China;

${ }^{4}$ Nanjing University of Information Science and Technology, Nanjing 210044,China;

ahvgaosong@qq.com, bsummerlily@nuist.edu.cn,

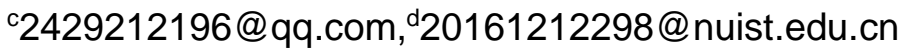

\section{Keywords:Haze discrimination methods;Atmospheric pollutants;Typical city}

Abstract This paper analyzes the distribution of haze under different conditions of winter in Jiangsu Province in 2014. Selected the city of Nanjing and Xuzhou as typical polluted cities, the analysis and comparison of different haze day's discrimination criteria are different. when the haze pollution is lighter, there are different methods, but when the haze pollution is relatively serious, the three methods of determine the haze day difference are almost same. The results showed that the concentration of pollution was higher in Nanjing and Xuzhou whose haze days were more.And the concentration of $\mathrm{PM}_{10}$ and $\mathrm{PM}_{2.5}$ exceeded the national standard $38.9 \%$ and $42.2 \%$ respectively in the Nanjing , 51.1\% and 55.6\% respectively in Xuzhou. Nanjing and Xuzhou are affected by both local and external sources.

\section{Introduction}

With the rapid growth of the economy and the accelerating urbanization process, regional compound air pollution was more serious. The heavy haze phenomenon caused by secondary pollutants such as increasing fine particulate matter ${ }^{[1]}$. Zhang et al. ${ }^{[2]}$ pointed out that people now see the fog and haze, is not a complete natural phenomenon, aerosol pollution is behind the main reason. Haze weather not only affect traffic safety, human health has also been a serious threat.

In different historical periods, WMO and other national meteorological agencies have given advice on distinguishing haze and fog ${ }^{[3]}$, which also uses the relative humidity as a supplementary criterion. In the WMO 1984 report, it is recommended that the relative humidity of haze be less than $80 \%{ }^{[4]}$. In recent years, there have been scholars identify the haze more concrete, there are two commonly used methods. One is the daily mean method, generally due to the relative humidity of less than $80 \%$ of the atmospheric turbidity caused by deterioration of visibility is caused by haze, relative humidity greater than $95 \%$ of the atmospheric turbidity caused by deterioration of visibility is caused by fog. When the relative humidity is between $80 \%$ and $95 \%$, the deterioration of the visibility caused by atmospheric turbidity is caused by the combination of fog and haze ${ }^{[5]}$. Another is the use of 14:00 when the measured value method, when the data to meet the visibility is less than $10 \mathrm{~km}$, relative humidity less than $90 \%$, recorded as a haze day ${ }^{[6]}$. When the relative humidity is less than $90 \%$, the fog is more difficult to form. This method can misty haze isolated, but also can be false haze in the haze. In the "haze observation and rating criteria" ${ }^{[7]}$ in the provisions of less than $10 \mathrm{~km}$ visibility, relative humidity less than $80 \%$ as haze. When the relative humidity is between $80 \%$ and $95 \%$, it is necessary to further identify the atmospheric composition index $\left(\mathrm{PM}_{2.5}\right.$ 
concentration, $\mathrm{PM}_{10}$ concentration, aerosol scattering coefficient and absorption coefficient). But the "standard" provides that the indicator is for the daily average or hour value. Accurate haze of the basis of discrimination, still need to conduct different methods of comparative study.

In this paper, the temporal and spatial distribution of haze in Jiangsu Province under different discriminative criteria is analyzed according to the meteorological observation data and the air pollutant concentration data of Jiangsu Province in the winter of 2014.

\section{Data}

\section{Site data}

In this paper, the observation data of 72 basic weather stations and 63 national control environmental monitoring stations in Jiangsu Province from October 2014 to April 2015 were selected, the time resolution of conventional meteorological observation data is $10 \mathrm{~min}$, and the time resolution of air pollutant concentration data is $1 \mathrm{~h}$.

Distribution characteristics of haze in Jiangsu Province

\section{Traditional haze day discrimination method and existing standard}

Combined with the current domestic and foreign haze identification method of the status quo, the traditional haze day discrimination method to do a summary, see Table 1. Method 4 is based on the existing haze day discrimination criteria, the index value applied to the daily average method.

Table1 Fog and haze discriminant method summary

\begin{tabular}{|c|c|}
\hline Solution1 & Daily average visibility $<10 \mathrm{~km}$, daily average relative humidity $<80 \%^{[3]}$ \\
\hline Solution2 & Daily average visibility $<10 \mathrm{~km}$, daily average relative humidity $<90 \%^{[4]}$ \\
\hline Solution3 & $\begin{array}{l}\text { 14:00 measured data visibility }<10 \mathrm{~km} \text {, relative humidity }<90 \% \text {, weather code } \\
05 \text { (haze), or when the weather code is recorded as } 01 \text { (exposed), } 02 \text { (frost), } 03 \\
\text { (ice), } 04 \text { (smoke), } 10 \text { (light fog), still adjusted as a haze day }{ }^{[6]}\end{array}$ \\
\hline Solution4 & $\begin{array}{l}\text { The daily average relative humidity }<80 \% \text {, daily average relative humidity of } \\
80 \% \sim 95 \%, \mathrm{PM} 2.5 \text { concentration }>75 \mu \mathrm{g} \cdot \mathrm{m}-3^{[7]}\end{array}$ \\
\hline
\end{tabular}

\section{Distribution characteristics of haze in Jiangsu Province}

Figure 1 shows the average haze distribution for individual sites in Jiangsu Province from October 2014 to April 2015, which are calculated by different methods. 86.1\% of the site by the method 2 statistics out of the largest haze day, $13.9 \%$ of the site by the method 3 statistics of the haze more, method 1 statistics of the haze number of days is less than the method 2 statistics out, $50 \%$ of the site method 1 and method 3 statistics out of the haze day, $12.5 \%$ of the site method 2 and method 3 statistics of the haze number of days. But the haze more serious areas, these three methods of the haze count more daily, indicating that these three methods are easier to determine the haze day, and in the haze is not serious areas, different methods caused by the larger differences. 

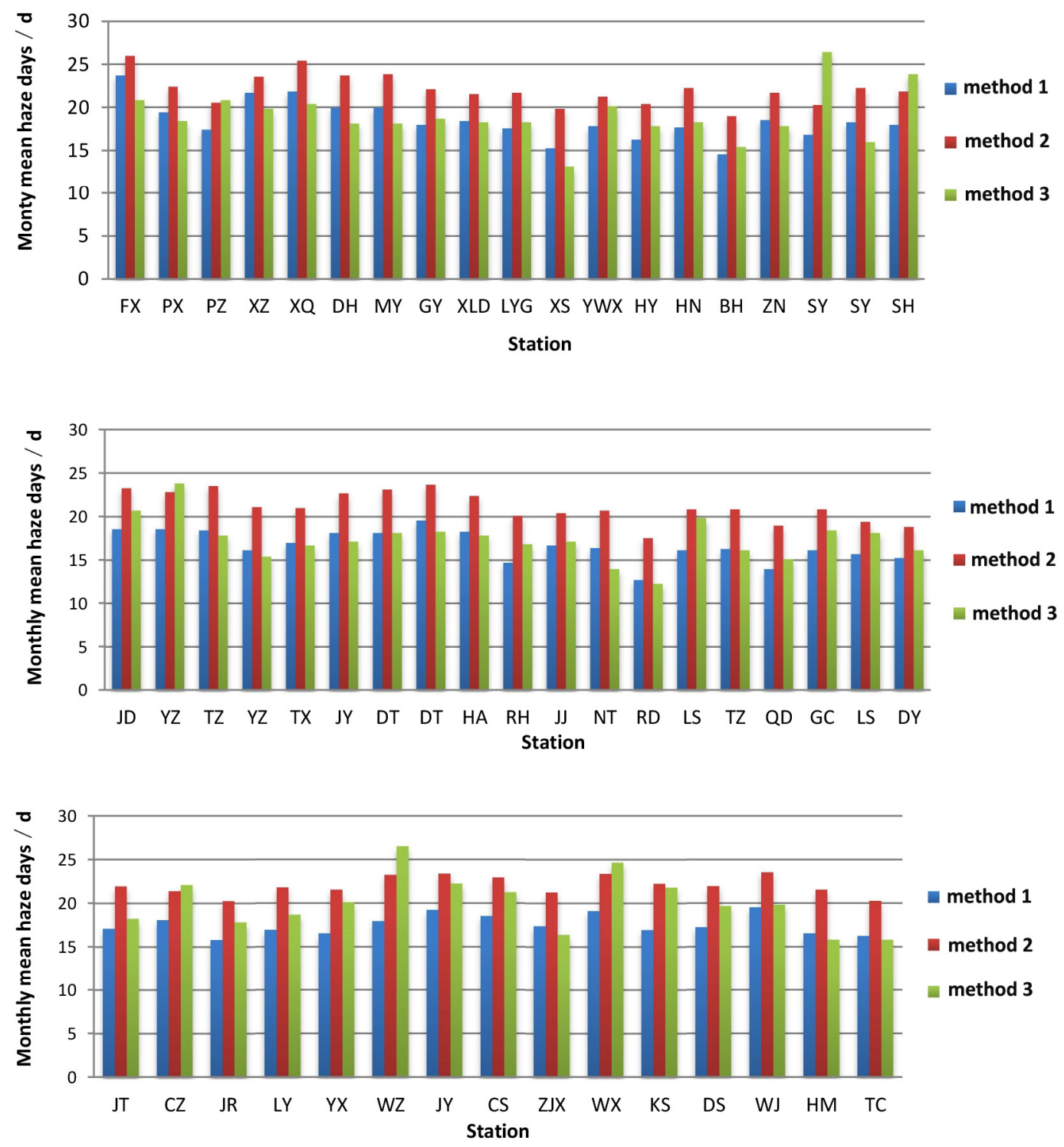

Fig.1 Monthly mean haze days distribution in different regions of Jiangsu from October 2014 to April 2015

\section{The contrast between traditional distinguish methods and "standard" for haze}

Figure 2 shows the number of haze days in different subcategories in the northern suburbs of Nanjing from October 2014 to April 2015. All four kinds of methods can reflect the development trend of the haze during the half year. Among them, the haze days of Oct, Nov, and Dec are the most, Jan is the least, followed by Feb, Mar, Apr. Indicating that the number of winter haze days is more than spring, when the number of haze days is more, these four methods are almost same. But the number counted by method 3 is the most during the slight haze days. And the number of haze counted by method 1 and method 4 (standard) is equivalent. It's indicated that when relative humidity between $80 \%-95 \%$, the case of $\mathrm{PM}_{2.5}$ concentration greater than $75 \mu \mathrm{g} \cdot \mathrm{m}^{-3}$ is less. Secondly, the figure also shows that the northern suburbs of Nanjing has experienced a serious haze pollution process in December 2014.

Figure 3 shows the haze days distinguished by different methods in Xuzhou during October 2014 to April 2015. Similar to the northern suburbs of Nanjing, the number of winter haze days in 
Xuzhou is more than spring. The difference is the number of haze days counted by method 4 (standard) are close to the method 1 during the heavy haze days, and the number of haze days counted by method 4 (standard) are close to the method 2 during the slight haze days. It's indicated that during the heavy haze days, the relative humidity between $80 \%-95 \%$, the case of $\mathrm{PM}_{2.5}$ concentration under than $75 \mu \mathrm{g} \cdot \mathrm{m}^{-3}$ is less. During the slight haze days, the relative humidity between $80 \%-95 \%$, the case of $\mathrm{PM}_{2.5}$ concentration under than $75 \mu \mathrm{g} \cdot \mathrm{m}^{-3}$ is more. Secondly, during the heavy haze days, the number of haze days distinguished by method 3 is far less than the other three methods, because the best visibility time of one day is 14:00, there's no haze pollution in this moment doesn't mean there's no haze pollution all day. But during the slight haze days, the number of haze days distinguished by method 3 is far more than the other three methods.

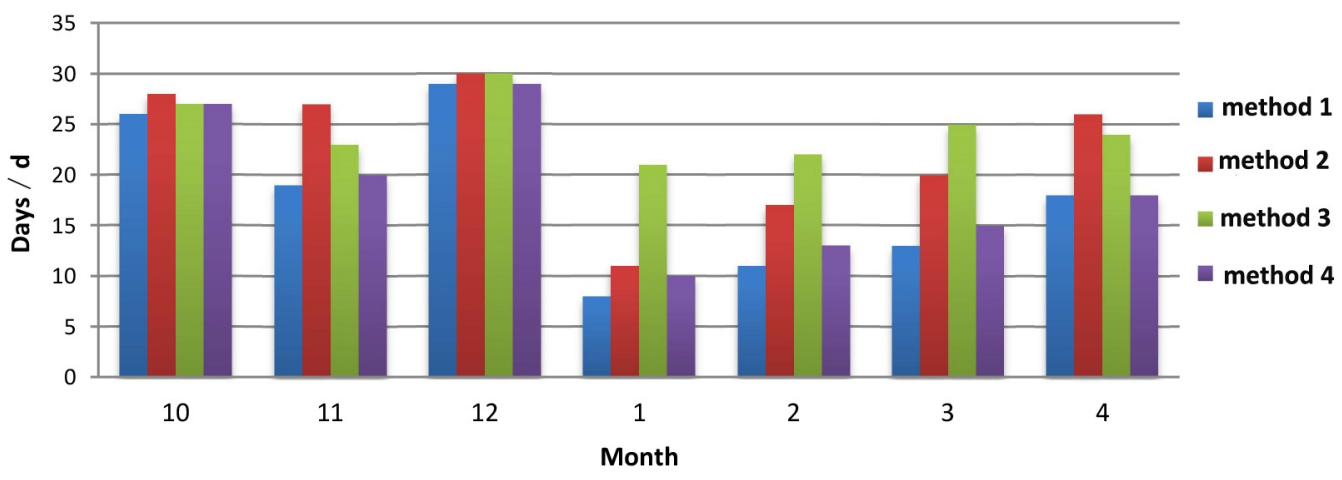

Fig.2 October 2014 - April 2015 haze days each month in northern suburbs of Nanjing

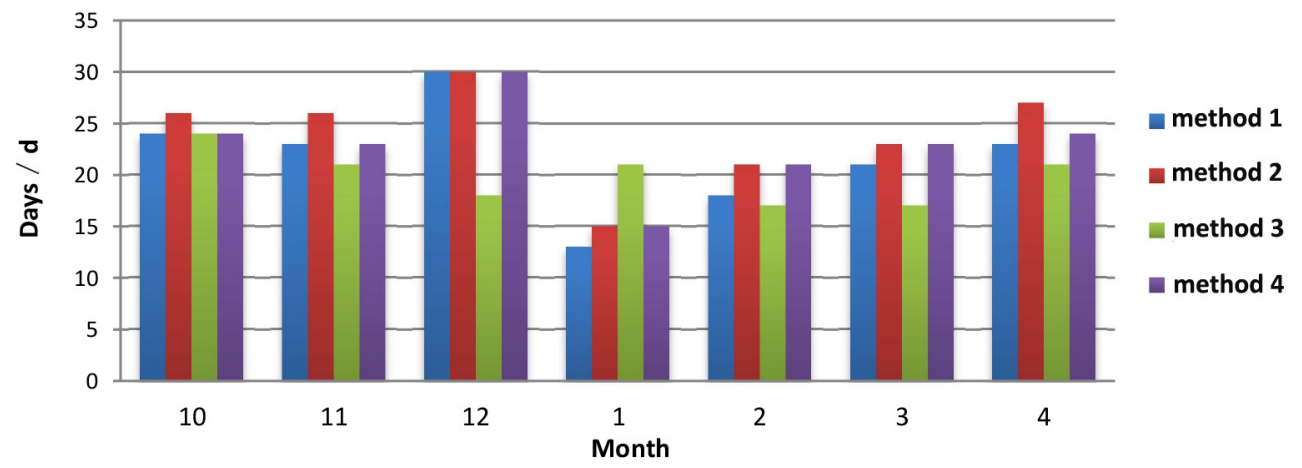

Fig.3 October 2014 - April 2015 haze days each month in Xuzhou

Table 2 shows the concentration of pollutant and exceeding standard rate in the cities of Jiangsu Province during October 2014 to April 2015, the maximum concentration of $\mathrm{NO}_{2}$ appeared in the Suzhou, it's exceeding standard rate is $55.6 \%$. The second concentration of $\mathrm{NO}_{2}$ appeared in Nanjing, it's exceeding standard rate is $32.2 \%$. There're higher concentration of $\mathrm{O}_{3}$ appeared in Yangzhou and Yancheng. There're higher concentration of $\mathrm{PM}_{10}$ appeared in Nanjing and Xuzhou. Xuzhou whose average concentration of $\mathrm{PM}_{10}$ reached $160.8 \mu \mathrm{g} \cdot \mathrm{m}^{-3}$ and exceeding standard rate reached $55.6 \%$ is the most serious. The exceeding standard rate of Nanjing reached $55.6 \%$. The most concentration area of $\mathrm{PM}_{2.5}$ appeared in Xuzhou, Huaian, Changzhou and Lianyungang. Among them, the maximum concentration of $\mathrm{PM}_{2.5}$ is $90.9 \mu \mathrm{g} \cdot \mathrm{m}^{-3}$, and the exceeding standard rate is 55.6\% appeared in Xuzhou. The most concentration area of $\mathrm{PM}_{2.5}$ appeared in Xuzhou and Nanjing whose the value $\mathrm{PM}_{2.5} / \mathrm{PM}_{10}$ is lesser, it's indicated that coarse particle of $\mathrm{PM}_{10}$ accounted for a larger share in these two areas. The maximum concentration of $\mathrm{SO}_{2}$ appeared in Xuzhou, and 
there're maximum exceeding standard rate reached 56.7\%. Among the whole province, there're minimum exceeding standard rate reached $2.2 \%$ in Nanjing and Suzhou, but the concentration of $\mathrm{SO}_{2}$ of these two cities is exceed Huaian and Lianyungang. In addition, there're better correspondence between the haze distribution and pollutant concentration. More serious pollution, especially the more serious pollution of particulate matter appeared in Nanjing and Xuzhou. The haze day space map of Jiangsu Province shows that there're higher number of haze days in Nanjing and Xuzhou, it's indicated that the increase of concentration for pollutants, especially particulate matter is a key factor for the occurrence of haze. So the following, selecting in Nanjing and Xuzhou as the typical polluted cities, discussing the relationship between their pollutants and meteorological, the daily and monthly changes.

Table2 Pollutant concentration and exceeding rate in Jiangsu city on October 2014 -2015

\begin{tabular}{|c|c|c|c|c|c|c|c|c|c|c|c|}
\hline \multirow[t]{2}{*}{ City } & \multicolumn{2}{|c|}{$\mathrm{SO}_{2}\left(* 10^{-9}\right)$} & \multicolumn{2}{|c|}{$\left.\mathrm{NO}_{2} * 10^{-9}\right)$} & \multicolumn{2}{|c|}{$\mathrm{O}_{3}\left(* 10^{-9}\right)$} & \multicolumn{2}{|c|}{$\mathrm{PM}_{10}\left(\mu \mathrm{g} \cdot \mathrm{m}^{-3}\right)$} & \multicolumn{2}{|c|}{$\mathrm{PM}_{2.5}\left(\mu \mathrm{g} \cdot \mathrm{m}^{-3}\right)$} & \multirow{2}{*}{$\mathrm{PM}_{2.5} / \mathrm{PM}_{10}$} \\
\hline & Average & Exceed & Average & Exceed & Average & Exceed & Average & Exceed & Average & Exceed & \\
\hline Nanjing & 33.6 & $2.2 \%$ & 56.1 & $32.2 \%$ & 62.3 & $7.8 \%$ & 133.8 & $38.9 \%$ & 77.2 & $42.2 \%$ & $57.7 \%$ \\
\hline Wuxi & 36.8 & $14.4 \%$ & 48.1 & $15.6 \%$ & 67.0 & $1 \%$ & 128.1 & $35.6 \%$ & 85.1 & $58.9 \%$ & $66.4 \%$ \\
\hline Zhenjiang & 31.3 & $6.7 \%$ & 52.3 & $26.7 \%$ & 70.7 & $4.4 \%$ & 121.2 & $25.6 \%$ & 75.0 & $42.2 \%$ & $73.2 \%$ \\
\hline Suzhou & 32.1 & $2.2 \%$ & 65.7 & $55.6 \%$ & 67.4 & $8.9 \%$ & 112.8 & $24.4 \%$ & 82.6 & $51.1 \%$ & $73.2 \%$ \\
\hline Nantong & 37.8 & $17.8 \%$ & 44.2 & $18.9 \%$ & 76.8 & $12.2 \%$ & 121.0 & $27.8 \%$ & 79.3 & $44.4 \%$ & $65.5 \%$ \\
\hline Yangzhou & 31.4 & $4.4 \%$ & 27.4 & $2.2 \%$ & 82.3 & $21.1 \%$ & 127.4 & $32.2 \%$ & 67.1 & $36.7 \%$ & $52.7 \%$ \\
\hline Yancheng & 32.5 & $11.1 \%$ & 25.1 & 0 & 94.9 & $34.4 \%$ & 118.5 & $21.1 \%$ & 75.2 & $40 \%$ & $63.5 \%$ \\
\hline Xuzhou & 60.6 & $56.7 \%$ & 45.5 & $1 \%$ & 70.6 & $6.7 \%$ & 160.8 & $51.1 \%$ & 90.9 & $55.6 \%$ & $56.5 \%$ \\
\hline Huaian & 28.2 & $4.4 \%$ & 28.1 & 0 & 67.3 & $2.2 \%$ & 134.7 & $31.1 \%$ & 89.1 & $57.8 \%$ & $66.1 \%$ \\
\hline Liangyungang & 27.3 & $24.4 \%$ & 41.4 & $8.8 \%$ & 77.3 & $13.3 \%$ & 134.2 & $30 \%$ & 88.3 & $51.1 \%$ & $65.8 \%$ \\
\hline Changzhou & 41.5 & $22.2 \%$ & 48.8 & $22.2 \%$ & 75.5 & $17.7 \%$ & 130.0 & $37.8 \%$ & 88.1 & $55.6 \%$ & $67.8 \%$ \\
\hline Taizhou & 39.3 & $6.7 \%$ & 31.9 & $2.2 \%$ & 57.0 & 0 & 116.1 & $22.2 \%$ & 80.3 & $53.3 \%$ & $69.1 \%$ \\
\hline Suqian & 34.9 & $8.9 \%$ & 45.3 & $13.3 \%$ & 63.9 & $2.2 \%$ & 136.2 & $31.1 \%$ & 77.3 & $41.1 \%$ & $56.8 \%$ \\
\hline
\end{tabular}

\section{Conclusion}

This paper uses data observed by the meteorological observation station and national control environment monitoring station, and makes a preliminary analysis about the haze days distribution and the pollution characteristics for typical urbans of Jiangsu Province during the winter of 2014. The following conclusions are obtained:

(1) The distribution of haze days distinguished by different method are almost same, The high number of haze days is mainly distributing in Nanjing and Xuzhou. During the slight haze days, there're difference among different method, the number of haze days counted by method 3 is always less than method 1 and method 2, because method 3 only considered the measured data at 14:00, the best visibility time of one day is 14:00, there's no haze pollution in this moment doesn't mean there's no haze pollution during other time. So the method 3 is not as reasonable as the 
method 1 and the method 2, and the method 1 is similar with the existing criterion of haze days. But these three methods is almost same during the heavy haze days, it's indicated that the rationalization of three methods.

(2)There're different haze pollution levels distinguished by different haze identification method. The distribution of haze level distinguished by method 3 has great difference with the other three methods, there're moderate and heavy haze occurred in Oct, but the other three statistic result showed slight haze. The result obtained by method 1,2,4 is almost same during the heave haze days, but the result obtained by method 2,4 is almost same during the slight haze days. There's no moderate haze result obtained by method 1, it's indicated that no occurrence of less than $3 \mathrm{~km}$ visibility, during the relative humidity less than $80 \%$.

(3) The concentration of pollutants especially the pollution of particulate matter is serious in the areas during heavy haze days, such as Nanjing and Xuzhou area. The concentration of $\mathrm{PM}_{10}$ and $\mathrm{PM}_{2.5}$ exceeded the national standard $38.9 \%$ and $42.2 \%$ respectively in the Nanjing, the concentration of $\mathrm{PM}_{10}$ and $\mathrm{PM}_{2.5}$ exceeded the national standard $51.1 \%$ and $55.6 \%$ respectively in Xuzhou. The two cities were the most polluted in January. Overall, there're lighter pollution and lesser number of haze days in Taizhou and Yancheng.

\section{References}

[1] $\mathrm{Wu}$ Dui. Hazy weather research in china in the last decade: A review. Acta Scientiae Circumstantiae, 32( 2) : 257-269

[2] Zhang Xiaoye, Sun Junying, Wang Yaqiang, et al. Factors contributing to haze and fog in China. Science China Press, 2013; 13: 1178- 1187

[3] Mao Minjuan, Liu Houtong, Xi Honghui, et al. The key factor research of haze with the combined application of the multielement data. Acta Scientiae Circumstantiae, 2013; 03: 806- 813

[4] World Meteorological Organization, WMO-No.266, Compendium of Lecture Notes for Training Class IV Meteorological Personnel Volume I I-Meteorology

[5] Wu Dui. Distinction between haze and fog in urban meteropolitans and hazy weather warnings. Environmental Science \& Technology, 2008; 09: 1- 7

[6] Wu Dui, Wu Xiaojing, Zhu Xiaoxiang, et al. Fog and Haze. Bejing: Meteorology Press, 2009; 53- 54

[7] QX/T 113-2010. 2010. Meteorological standard of the People' s Republic of China, Observation and forecast levels of haze. Bejing: Meteorology Press (in Chinese) 